\title{
Different Isoforms of the Non-Integrin Laminin Receptor Are Present in Mouse Brain and Bind PrP
}

\author{
Steve Simoneau ${ }^{1, a}$, Stéphane Haïk1,a, Christoph \\ Leucht $^{2}$, Dominique Dormont ${ }^{1}$, Jean-Philippe \\ Deslys ${ }^{1}$, Stefan Weiss ${ }^{2}$ and Corinne Lasmézas ${ }^{1, *}$ \\ ${ }^{1}$ CEA, Département de Recherche Médicale, DSV, \\ B.P. 6, F-92 265 Fontenay-aux-Roses Cedex, France \\ ${ }^{2}$ Laboratorium für Molekulare Biologie (Genzentrum), \\ Institut für Biochemie der LMU München, \\ Feodor-Lynen Str. 25, D-81377 München, Germany \\ *Corresponding author
}

The prion protein (PrP) plays a central role in prion diseases, and identifying its cellular receptor appears to be of crucial interest. We previously showed in the yeast two-hybrid system that PrP interacts with the $37 \mathrm{kDa}$ precursor (LRP) of the high affinity $67 \mathrm{kDa}$ laminin receptor (LR), which acts as the cellular receptor of PrP in cellular models. However, among the various isoforms of the receptor that have been identified so far, those which are present in the central nervous system and which bind PrP are still unknown. In this study, we have purified mouse brain fractions enriched in the laminin receptor and have performed overlay assays in order to identify those isoforms that interact with the prion protein. We demonstrate (i) the presence, in mouse brain, of several isoforms of the LRP/LR corresponding to different maturation states of the receptor $(44,60,67$ and $220 \mathrm{kDa})$ and (ii) the binding of all of these isoforms to PrP. Our data strongly support a physiological role of the laminin receptor/ PrP interaction in the brain and highlight its relevance for transmissible spongiform encephalopathies. Key words: Brain / Cellular receptor/Laminin/LRP/LR/ Prion protein.

A fundamental event in the pathogenesis of human and animal prion diseases is the conformational modification of a normal host-encoded protein ( $\mathrm{PrPc}$ ) from a soluble form to an aggregated, partially protease-resistant form termed PrPsc enriched in $\beta$-sheeted structures (for review see Prusiner, 1998). The misfolded isoform ( $\mathrm{PrPsc}$ ) of the prion protein accumulates in the central nervous system and in other areas, such as the lymphoreticular system, during the development of the disease. PrPsc is thought to

a These authors contributed equally to this work be a major component of the causative agent of transmissible spongiform encephalopathies (TSE), also called prion diseases. Proteinase $\mathrm{K}$ resistance is a hall mark of PrPsc (Prusiner et al., 1984) and PrP mutants causing familial prion diseases (Gauczynski et al., 2002). Molecules interacting with PrP (for review see Gauczynski et al., 2001a) that could play a role in the replication of the infectious particle, as well as the precise location where the conversion from $\mathrm{PrP}^{\mathrm{c}}$ to $\mathrm{PrPsc}$ take place, have to be identified (Caughey and Raymond, 1991; Telling et al., 1995). It has been shown that the normal isoform, $\mathrm{PrPc}$, plays a central role in prion diseases: (i) PrP knockout mice are resistant to prion infection (Büeler et al., 1993); (ii) when transgenic mice expressing different levels of $\mathrm{PrPc}^{\mathrm{c}}$ are infected with the agent of prion diseases, the duration of the incubation period is inversely proportional to the level of $\mathrm{PrPc}^{\mathrm{c}}$ expressed; (iii) the PrP gene of the host controls the species barrier (Scott et al., 1989; Prusiner, 1993) and (iv) $\mathrm{PrP}^{\mathrm{c}}$ expression is necessary for prion-induced neurodegeneration (Brandner et al., 1996). Thus, characterization of the cellular receptor for the prion protein appears to be of crucial interest for understanding the mechanisms of prion replication, CNS invasion, and neurodegeneration characteristically linked to prion diseases. In the yeast two-hybrid system, we have identified the $37 \mathrm{kDa}$ precursor (LRP) of the $67 \mathrm{kDa}$ laminin receptor (LR) as a protein which interacts directly with $\mathrm{PrPc}^{\mathrm{c}}$ (Rieger et al., 1997). Coexpression of both LRP and PrP in insect and mammalian cells has confirmed this interaction (Rieger et al., 1997). Furthermore, the level of LRP, which has been described previously as a receptor for the Sindbis virus on mammalian cells (Wang et al., 1992), is increased in organs that support prion replication and PrPsc accumulation in experimental scrapie or bovine spongiform encephalopathy (BSE)-infected animals (Rieger et al., 1997). In cellular models including primary cultures and neuronal cell lines, we demonstrated that LRP acts as the cellular receptor for $\mathrm{PrP}^{\mathrm{c}}$, mediating the binding and internalization of recombinant PrPc (Gauczynski et al., 2001b; Hundt et al., 2001). We identified interaction domains of the cellular prion protein with LRP and proposed a model for the interaction complex of PrP with LRP/LR. In this model, heparan sulfate proteoglycans (HSPGs) would act as cofactors/co-receptors for the binding and internalization process of PrP (Hundt et al., 2001) and may account for the LRP/LR polymorphism. Additional heparan sulfate binding sites have been identified in the cellular prion protein (Warner et al., 2002). 
The polypeptide predicted from the non-integrin laminin receptor cDNA sequence consists of 295 amino acids and the in vitro translation of selectively hybridized mRNA produced a protein with an apparent molecular mass of $37 \mathrm{kDa}$ on sodium dodecyl sulfate-polyacrylamide gel electrophoresis (SDS-PAGE) (Rao et al., 1989). However, other isoforms of the laminin receptor, displaying higher molecular masses, have also been described (Castronovo et al., 1991; Landowski et al., 1995; Menard et al., 1997; Buto et al., 1998). One of these isoforms, the $67 \mathrm{kDa}$ high affinity laminin receptor (LR: presumably the mature form of the receptor), is thought to arise from the heterodimerization of its precursor molecule, the $37 \mathrm{kDa}$ LRP, with a still unidentified molecule (Buto et al., 1998). The $67 \mathrm{kDa} \mathrm{LR}$ is believed to be the functional isoform of the receptor regarding its ability to mediate strong attachement of cells to laminin (Lesot et al., 1983; Malinoff and Wicha, 1983; Rao et al., 1983), to be overexpressed on cancer cell sufaces, and to promote the invasive and metastatic capacity of these cells (Menard et al., 1997). Thus, it is of crucial importance to investigate whether this isoform is normally expressed in mouse brain and whether this isoform binds PrP.

We prepared brain protein fractions from uninfected mouse brain homogenates (abbreviated here as AS50: $50 \%$ ammonium sulfate fraction) according to Martins et al. (1997). Using antibodies recognizing specifically the LRP (W3) and the LR (ab711), we investigated which isoforms of the laminin receptor could be detected in the AS50 brain fraction. With these polyclonal antibodies, we identified 4 different isoforms of the receptor, migrating at $44 \mathrm{kDa}$ (Figure 1, lane 2), 60 and $67 \mathrm{kDa}$ (Figure 1, lane 1), and $220 \mathrm{kDa}$ (Figure 1, lane 1). The $44 \mathrm{kDa}$ isoform, which has been observed previously in cellular extract such as A431 human epidermoid carcinoma cells, corresponds to the precursor receptor LRP (Rao et al., 1989; Buto et al., 1998). The 60 and $67 \mathrm{kDa}$ doublet bands have also been detected in A431 cellular extract and other cancer tissues (Castronovo, 1993; Buto et al., 1998). The 60 kDa peptide was described as a differentially phosphorylated isoform of the mature $67 \mathrm{kDa}$ Laminin receptor (Buto et al., 1998). The last isoform, the $220 \mathrm{kDa}$ protein, presumably corresponds to an oligomeric form of the LR. The specificity of these antibodies was confirmed since no bands were detected using the secondary antibody alone (Figure 1, lane 3). It is interesting to note the different spectrum of recognition of the laminin receptor with the two antibodies used. In the first case, Ab711, a polyclonal antibody directed against amino acids 263-282 of the C-terminal domain of human laminin receptor (Wewer et al., 1987) recognizes only the higher molecular mass isoforms of the receptor while the antibody $\mathrm{W} 3$ raised against full-length LRP (Rieger et al., 1997) recognizes only LRP. This suggests that the corresponding epitopes are exposed differentially depending on whether the receptor is in a precursor or mature state, and whether it is heterodimerized or oligomerized.

We next wanted to identify which laminin receptor iso-

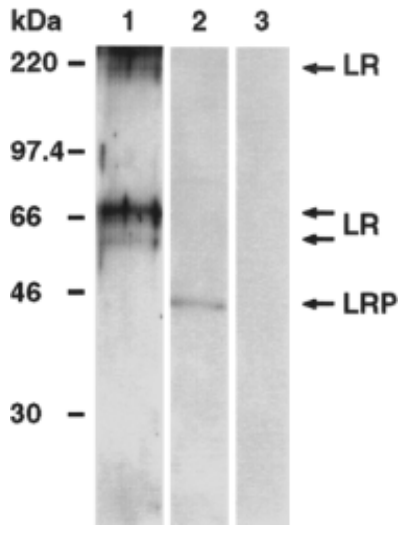

Fig. 1 Antibodies Directed against the Non-Integrin Laminin Receptor Recognize Proteins with Molecular Masses of 44, 60, 66 , and $220 \mathrm{kDa}$.

A mouse brain fraction partially purified by ammonium sulfate precipitation $(20 \mu \mathrm{g})$ was electrophoretically separated and analyzed by Western blotting using two polyclonal antibodies recognizing either the $37 \mathrm{kDa}$ laminin receptor precursor or the mature $67 \mathrm{kDa}$ laminin receptor. The following polyclonal antibodies were employed in this study: Ab711, directed against the peptide P20A (PTEDWSAQPATEDWSAAPTA) amino acids 263-282 from the C-terminal domain of human laminin receptor cDNA, and W3, raised against full-length LRP protein.

Methods: purification of murine laminin receptor by successive ammonium sulfate precipitations. A $20 \%$ murine brain homogenate was prepared as previously described (Martins et al., 1997). Briefly, mouse brains were homogenized in a $20 \%$ ratio in $50 \mathrm{~mm}$ Tris- $\mathrm{HCl} \mathrm{pH} \mathrm{7.4,} \mathrm{0.2 \%} \mathrm{sodium} \mathrm{deoxycholate,} 0.5 \%$ Triton X-100, $1 \mathrm{~mm}$ aproptinin, $1 \mathrm{~mm}$ leupeptin, $1 \mathrm{~mm}$ PMSF, and $1 \mathrm{~mm}$ benzamidine and then centrifuged at $12000 \mathrm{~g}$ for $30 \mathrm{~min}$. The supernatant was then subjected to successive precipitations with $30 \%$ and $50 \%$ ammonium sulfate salt. The $50 \%$ fraction precipitate (AS50), was then dissolved in $20 \mathrm{~mm}$ Tris- $\mathrm{HCl}, \mathrm{pH} 7$. 4 , and $120 \mathrm{~mm} \mathrm{NaCl}$. Protein samples were separated on $12 \%$ SDS-PAGE gels and transferred to nitrocellulose (Schleicher \& Schuell; Dassel, Germany). The nitrocellulose blots were then blocked in Blotto [phosphate-buffered saline (PBS) containing $5 \%$ dry skim milk powder and $0.1 \%$ Tween 20 ] for $1 \mathrm{~h}$ and then rinsed with PBS-Tween. Blots were then exposed for $1 \mathrm{~h}$ to antilaminin receptor polyclonal antibodies Ab711 (Abcam Ltd., Cambridge, UK) and W3 (Rieger et al., 1997). The blots were washed three times and then exposed to anti-rabbit peroxidasecoupled secondary antibodies (Southern Biotechnology, Birmingham, USA; diluted 1:10 000). Peroxidase reactions were detected using enhanced chemiluminescence according to protocols provided by the manufacturer (Amersham).

form could interact with PrP. To this end we performed overlay assays according to Martins et al. (1997) using human GST-PrP fusion protein (GST-PrP) and the AS50 brain fraction. The integrity of the recombinant protein was first verified by western blot (Figure 2a, lane 1). For the overlay, the proteins present in the AS50 fraction were separated by gel electrophoresis and overlaid with recombinant GST::PrP. Then, using a polyclonal antibody directed against GST, we examined the binding of GST::PrP to several proteins displaying molecular masses of approximately $44 \mathrm{kDa}$ and 60/67 kDa (Figure 2b, 
a

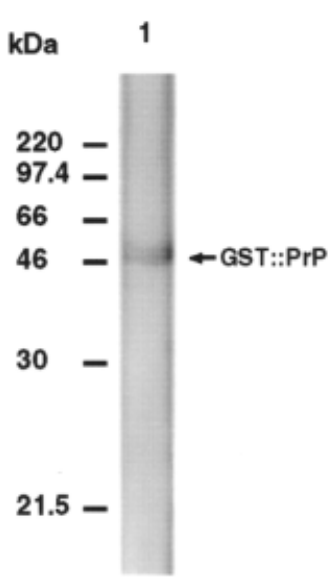

b

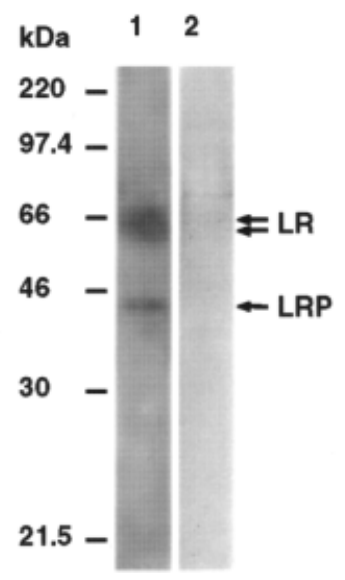

C

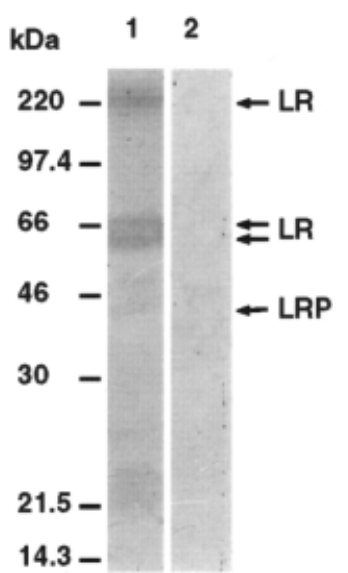

Fig. 2 All Proteins Recognized by Anti-Laminin Receptor Antibodies in the AS50 Brain Fraction Bind PrP.

(a) Verification of the integrity of the recombinant GST::PrP band probed with the PrP-specific antibody 3F4 (lane1). (b) Proteins from the AS50 brain extract were separated by Western blot and overlaid either with recombinant GST::PrP (lane 1) or with control solution (lane 2). The binding of the GST::PrP was visualized with a polyclonal antibody directed against GST. (c) Overlay of [35S]-radiolabeled GST::PrP (lane 1) and GST (lane 2) on immobilized proteins of the AS50 brain fraction.

Methods: all overlay assays were performed on nitrocellulose blots with proteins separated by SDS-PAGE. Blots were incubated with $4 \mathrm{\mu g} / \mathrm{ml}$ of recombinant GST::PrP in PBS containing $0.05 \%$ Tween 20 for $3 \mathrm{~h}$ at room temperature. After three washes in PBS-Tween $(0.05 \%)$, the immunoblots were further incubated with an anti-GST polyclonal antibody for $1 \mathrm{~h}$. The reactive bands were visualized with anti-rabbit peroxidase-coupled antibodies. Immunoblots were developed by enhanced chemiluminescence. Overlay assays accomplished with [ $\left.{ }^{35} \mathrm{~S}\right]$-radiolabeled proteins were performed using the same methodology without antibodies, and revealed by exposing Xray films to the blots.

Purification and expression of heterologous proteins (GST::PrP and GST): recombinant GST::huPrP23-230 was synthesized in Sf9 cells by infection with the recombinant baculovirus AcSG2T::huPrP23-230 and radiolabeled in the presence of [35S]-methionine as described for the GST::haPrP23-231 (Weiss et al., 1995). Radiolabeling of GST was performed as for GST::huPrP23-230. Both proteins were purified to homogeneity as previously described in Weiss et al. (1995).

lane 1, arrows). The molecular mass of the bands detected corresponded exactly to those detected with LRP/LR antibodies (compare with Figure 1). A mock overlay revealed no unspecific binding of the anti-GST antibody to the AS50 brain fraction (Figure 2b, lane 2). In order to strengthen the finding that PrP binds to proteins exhibiting characteristic molecular masses for the different LR isoforms in SDS-PAGE (Figure 1), we repeated the overlay assay using [ $\left.{ }^{35} \mathrm{~S}\right]$-radiolabeled GST::PrP which gives a better resolution of the signal. Validating our previous results, the [ $\left.{ }^{35} \mathrm{~S}\right]$-labeled GST::PrP bound to several proteins migrating in the gel at $60 \mathrm{kDa}, 67 \mathrm{kDa}, 220 \mathrm{kDa}$, and weakly to the $44 \mathrm{kDa}$ protein (Figure $2 \mathrm{c}$, lane 1 ), again demonstrating the interaction between PrP and the laminin receptor. As a control, the specific interaction of GST::PrP to the proteins of the AS50 fraction was verified using [ ${ }^{35}$ S]-radiolabeled GST (Figure 2c, lane 2).

In this study, we identified those isoforms of the high affinity laminin receptor that are expressed in the murine central nervous system and showed that all these isoforms interact with PrP. We demonstrated the specific binding of both non-radiolabeled and radiolabeled GST::PrP to the $44,60 / 67$, and $220 \mathrm{kDa}$ isoforms. The $60 / 67 \mathrm{kDa}$ isoform, referred to as the mature isoform, is considered to be the functional entity. Therefore, these results are suggestive of an effective role of the $\mathrm{PrP} / 67 \mathrm{kDa} \mathrm{LR}$ interaction in the metabolism of $\mathrm{PrPc}^{\mathrm{c}}$ and presumably its pathological counterpart PrPsc. Hence, further investigations of the laminin receptor as a potential therapeutic target for TSE pathologies have to be considered. Moreover, a parallel can be established between our present demonstration and a previously published study demonstrating the binding of PrP to a $60 / 66 \mathrm{kDa}$ protein found in the AS50 murine brain fraction (Martins et al., 1997). In their study, Martins et al. exploited a concept called complementary hydropathy, by which peptides encoded by complementary DNA strands bind to each other, and can be used to produce peptides that mimic the binding site of a receptor. Surprisingly, both receptor candidates, i.e. the laminin receptor and the protein isolated by complementary hydropathy (Martins et al., 1997) are found in the 50\% ammonium sulfate brain extract, share the same electrophoresis pattern with a doublet band at $60 / 67 \mathrm{kDa}$, and exhibit the same PrP binding properties in overlay assays. The $66 \mathrm{kDa}$ band of the protein isolated by complementary hydropathy was recently identified as the murine stress-inducible protein 1 (STI1) (Zanata et al., 2002).

Our study confirms that the non-integrin $67 \mathrm{kDa}$ laminin receptor is present in murine brain and that it binds PrP. This fact along with our previous study (Gauczynski et al., 2001b) demonstrating that the laminin receptor acts as the cell surface receptor internalizing 
PrP supports the crucial role of this receptor as the cell surface receptor for the prion protein in the brain. In order to better comprehend the pathogenesis of prion diseases and to allow new approaches in therapeutics, the physiological role of the interaction of PrP with the various isoforms of the receptor $(44,60 / 67$ and $220 \mathrm{kDa})$ will have to be examined by further biochemical and cell biological studies.

\section{Acknowledgments}

This study was supported by grants BIOMED PL-97-6054 and QLRT-2000-02085 of the European Union. S. Weiss acknowledges the support by grants 01-KO-0106, 0312876 (BMBF), LMU 3 and 4 (Bavarian Prion Research Foundation) and thanks R. Grosschedl and E.-L. Winnacker for valuable advice and continuous support.

\section{References}

Brandner, S., Isenmann, S., Raeber, A., Fischer, M., Sailer, A., Kobayashi, Y., Marino, S., Weissmann, C., and Aguzzi, A. (1996). Normal host prion protein necessary for scrapie-induced neurotoxicity. Nature 379, 339-343.

Büeler, H., Aguzzi, A., Sailer, A., Greiner, R.A., Autenried, P., Aguet, M., and Weissmann, C. (1993). Mice devoid of PrP are resistant to scrapie. Cell 73, 1339-1347.

Buto, S., Tagliabue, E., Ardini, E., Magnifico, A., Ghirelli, C., van den Brule, F., Castronovo, V., Colnaghi, M.I., Sobel, M.E., and Menard, S. (1998). Formation of the 67-kDa laminin receptor by acylation of the precursor. J. Cell. Biochem. 69, 244-251.

Castronovo, V. (1993). Laminin receptors and laminin-binding proteins during tumor invasion and metastasis. Invasion Metastasis 13, 1-30.

Castronovo, V., Taraboletti, G., and Sobel, M.E. (1991). Functional domains of the $67-\mathrm{kDa}$ laminin receptor precursor. J. Biol. Chem. 266, 20440-20446.

Caughey, B., and Raymond, G.J. (1991). The scrapie-associated form of PrP is made from a cell surface precursor that is both protease and phospholipase-sensitive. J. Biol. Chem. 266, $18217-18223$.

Gauczynski, S., Hundt, C., Leucht, C., and Weiss, S. (2001a). Interaction of prion proteins with cell surface receptors, molecular chaperones and other molecules. Adv. Prot. Chem. 57, 229-272.

Gauczynski, S., Peyrin, J.M., Haik, S., Leucht, C., Hundt, C., Rieger, R., Krasemann, S., Deslys, J.P., Dormont, D., Lasmezas, C.I., and Weiss, S. (2001b). The 37-kDa/67-kDa laminin receptor acts as the cell-surface receptor for the cellular prion protein. EMBO J. 20, 5863-5875.

Gauczynski, S., Krasemann, S., Bodemer, W., and Weiss, S. (2002). Recombinant human prion protein mutants huPrP D178N/M129 (FFI) and huPrP+9OR (fCJD) reveal proteinase K resistance. J. Cell. Sci. 115, 4025-4036.

Hundt, C., Peyrin, J.M., Haik, S., Gauczynski, S., Leucht, C., Rieger, R., Riley, M.L., Deslys, J.P., Dormont, D., Lasmezas, C.I., and Weiss, S. (2001). Identification of interaction domains of the prion protein with its $37-\mathrm{kDa} / 67-\mathrm{kDa}$ laminin receptor. EMBO J. 20, 5876-5886.

Landowski, T.H., Dratz, E.A., and Starkey, J.R. (1995). Studies of the structure of the metastasis-associated $67 \mathrm{kDa}$ laminin binding protein: fatty acid acylation and evidence supporting dimerization of the $32 \mathrm{kDa}$ gene product to form the mature protein. Biochemistry 34, 11276-11287.

Lesot, H., Kühl, U., and von der Mark, K. (1983). Isolation of a laminin-binding protein from muscle cell membranes. EMBO J. 2, 861-865.

Malinoff, H.L., and Wicha, M.S. (1983). Isolation of a cell surface receptor protein for laminin from murine fibrosarcoma cells. J. Cell. Biol. 96, 1475-1479.

Martins, V.R., Graner, E., Garcia-Abreu, J., Souza, S.J.D., Mercandante, A.F., Veiga, S.S., Zanata, S.M., Neto, V.M., and Brentani, R.R. (1997). Complementary hydropathy identifies a cellular prion protein receptor. Nature Med. 3, 1376-1382.

Menard, S., Castronovo, V., Tagliabue, E., and Sobel, M.E. (1997). New insights into the metastasis-associated $67 \mathrm{kD}$ laminin receptor. J. Cell. Biochem. 67, 155-165.

Prusiner, S.B. (1993). Transgenetic investigations of prion diseases of humans and animals. Phil. Trans. R. Soc. Lond. 339, $239-254$.

Prusiner, S.B. (1998). Prions. Proc. Natl. Acad. Sci. USA 95, $13363-13383$.

Prusiner, S.B., Groth, D.F., Bolton, D.C., Kent, S.B., and Hood, L.E. (1984). Purification and structural studies of a major scrapie prion protein. Cell 38, 127-134.

Rao, C.N., Castronovo, V., Schmitt, M.C., Wewer, U.M., Claysmith, A.P., Liotta, L.A., and Sobel, M.E. (1989). Evidence for a precursor of the high-affinity metastasis-associated murine laminin receptor. Biochemistry 28, 7476-7486.

Rao, N.C., Barsky, S.H., Terranova, V.P., and Liotta, L.A. (1983). Isolation of a tumor cell laminin receptor. Biochem. Biophys. Res. Commun. 111, 804-808.

Rieger, R., Edenhofer, F., Lasmezas, C.I., and Weiss, S. (1997). The human $37-\mathrm{kDa}$ laminin receptor precursor interacts with the prion protein in eukaryotic cells. Nature Med. 3, 13831388.

Scott, M.R.D., Foster, D., Mirenda, C., Serban, D., Coufal, F., Walchii, M., Torchia, M., Groth, D., Carlson, G., DeArmond, S.J., Westaway, D., and Prusiner, S.B. (1989). Transgenic mice expressing hamster prion protein produce species-specific scrapie infectivity and amyloid plaques. Cell 59, 847-857.

Telling, G.C., Scott, M., Mastrianni, J., Gabizon, R., Torchia, M., Cohen, F.E., DeArmond, S.J., and Prusiner, S.B. (1995). Prion propagation in mice expressing human and chimeric PrP transgenes implicates the interaction of cellular PrP with another protein. Cell 83, 79-90.

Wang, K.S., Kuhn, R.J., Strauss, E.G., Ou, S., and Strauss, J.H. (1992). High-affinity laminin receptor is a receptor for Sindbis virus in mammalian cells. J. Virol. 66, 4992-5001.

Warner, R.G., Hundt, C., Weiss, S., and Turnbull, J.E. (2002). Identification of the heparan sulfate binding sites in the cellular prion protein. J. Biol. Chem. 277, 18421-18430.

Weiss, S., Famulok, M., Edenhofer, F., Wang, Y.H., Jones, I.M., Groschup, M., and Winnacker, E.L. (1995). Overexpression of active Syrian golden hamster prion protein $\mathrm{PrPc}$ as a glutathione S-transferase fusion in heterologous systems. J. Virol. 69, 4776-4783.

Wewer, U.M., Taraboletti, G., Sobel, M.E., Albrechtsen, R., and Liotta, L.A. (1987). Role of laminin receptor in tumor cell migration. Cancer Res. 47, 5691-5698.

Zanata, S.M., Lopes, M.H., Mercadante, A.F., Hajj, G.N., Chiarini, L.B., Nomizo, R., Freitas, A.R., Cabral, A.L., Lee, K.S., Juliano, M.A. et al. (2002). Stress-inducible protein 1 is a cell surface ligand for cellular prion that triggers neuroprotection. EMBO J. 21, 3307-3316.

Received January 31, 2002; accepted December 2, 2002 